\title{
ECONOMIA SOLIDÁRIA COMO MODO PÓS-CAPITALISTA DE DESENVOLVIMENTO
}

Marcos Arruda ${ }^{1}$

Só é possível surgir um mundo pós-capitalista de dois vetores que se entre-tecem: um, as contradições do capitalismo, um sistema que aliena os seres humanos, as comunidades e as nações, de si próprias e dos seus próximos, lançando uns contra os outros pela cobiça, voracidade e competição; o outro, a 'vontade coletiva nacional-popular' (Gramsci) que expressa a consciência crítica dos povos, quando maduros, num movimento maciço pela transformação.

Ao longo de séculos, desde que o sistema do capital prevaleceu na história humana, tantos os trabalhadores empregados como os desempregados têm procurado formas alternativas de organizar o consumo, a produção, o comércio, o acesso e a gestão dos bens e recursos produtivos. Chamo isto de 'economia do trabalho emancipado', o oposto da 'economia do capital'. Experiências relevantes emergiram no passado, com a Comuna de Paris, a cooperativa de Rochdale, Scotland, e outras. Elas praticavam modos inovadores de comércio, produção, distribuição e, mais tarde, consumo e finanças. Tudo isto fundado numa educação voltada para o empoderamento e a autoestima dos trabalhadores, a cooperação e a solidariedade.

O desafio para as classes trabalhadoras ao longo de mais de dois séculos de opressão, exploração e alienação, tem sido não só transformar a forma no nível micro, mas também como criar ambientes propícios para o desenvolvimento de formas meso e macro de organização da economia, baseado na premissa de que A VIDA e sua evolução, na forma de seres cosmopoiéticos e autopoiéticos, é o verdadeiro sentido do saber, trabalho e criatividade humanos. Os povos trabalhadores, portanto, devem tornar-se o sentido e o agente nuclear das relações e das práticas socioeconômicas. O empoderamento econômico das mulheres e homens trabalhadores é a base para seu empoderamento político e, em consequência, é uma dimensão essencial da verdadeira democracia.

O movimento de Economia Solidária na América Latina e no Caribe tem aprendido das formas de organização da vida e do trabalho, tanto dos povos indígenas quanto dos modos europeus de organizar a produção e os fluxos econômicos de bens e serviços com base na autogestão, na cooperação e na solidariedade. O mapeamento de cooperativas, associações e entidades de consultoria solidária estimaram em quase vinte mil iniciativas trabalhando de forma colaborativa, gerando uma renda anual de cerca de $\mathrm{R} \$ 8$ bilhões. Desde 2003 o Fórum Brasileiro

\footnotetext{
${ }^{1}$ Economista e educador do PACS - Instituto Políticas Alternativas para o Cone Sul (Rio de Janeiro) e associado ao Instituto Transnacional (Amsterdam). Atua nos movimentos de Economia Solidária, de Ecovilas e Cidades em Transição desde meados dos anos 90 .
} 
de Economia Solidária ${ }^{2}$ tem conseguido promover a organização autônoma das e dos traballhadores a fim de estabelecerem fluxos socioeconômicos, e manterem um diálogo dinâmico com a Secretaria Nacional de Economia Solidária, do Ministério do Trabalho e Emprego.

Semelhantes articulações têm emergido em outros países do continente. A interação entre ativistas, pesquisadores e consultores em Economia Solidária levou à criação da Rede Intercontinental para a Promoção da Economia Social Solidária (RIPESS) ${ }^{3}$, atualmente organizada em seis continentes, entre os quais a América Latina e o Caribe.

No mundo atual, a Economia Solidária é um movimento plural, que envolve pessoas que a consideram simplesmente um mecanismo social de compensar pelo desemprego e pelas desigualdades de renda e riqueza; mas também envolvem pessoas e organizações que promovem o potencial da Economia Solidária de tornar-se um modo pós-capitalista de conceber e organizar a produção, o desenvolvimento e a reprodução da vida no Planeta, em equilíbrio harmônico com os ecossistemas.

Os dois maiores desafios para a Economia Solidária são:

1. Objetivo: como operar solidária e sustentavelmente, no contexto do sistema dominante - que é centrado no crescimento ilimitado do consumo e da produção, e é liderado pela economia das empresas como 'pessoas jurídicas', 'do mercado' e do lucro; e, ao mesmo tempo, como construir, já, uma economia centrada no planejamento do consumo e da produção, ligados às necessidades e desejos das pessoas e comunidades, à economia do suficiente, e à lógica da abundância na sobriedade.

2. Subjetivo: como operar, ao mesmo tempo, a transformação interior das pessoas de paradigma, de conhecimento de si, do outro e da sociedade, de sentido da vida pessoal e social, - sendo continuamente bombardeado pela cultura patriarcal do egoísmo, da arrogância e da voracidade.

A solução me parece estar em referenciar a atividade econômica não mais do desenvolvimento da empresa individual, mas sim no desenvolvimento das pessoas e da comunidade, subindo delas até o nível do País, do continente e da espécie humana no planeta. Recentrar a economia e o desenvolvimento no humano - individual e social - este é o portal para o novo mundo já em gestação no momento presente.

\footnotetext{
${ }^{2}$ http://www.fbes.org.br: o FBES, Fórum Brasileiro de Economia Solidária, está presente em todo o Brasil, com mais de 160 fóruns municipais, microrregionais e estaduais, envolvendo diretamente mais de 3.000 iniciativas de Economia Solidária, 500 organizações de consultoria solidária, 12 governos estaduais e 200 municipais através da Rede de Gestores em Economia Solidária.

${ }^{3} \mathrm{http}: / /$ www.ripess.org/contact-us/?lang=en
} 


\section{BIBLIOGRAFIA}

Arruda, Marcos (org.), "Intercambiando Visiones de una Economía Responsible, Plural y Solidaria", 2009, PACS/ALOE/FPH, livreto escrito como resumo do saber coletivo do Grupo de Trabalho sobre Visão, de ALOE (Aliança Internacional por uma Economia Responsável, Plural e Solidária).

Arruda, Marcos (org.), "A Non-Patriarchal Economy is Possible - Looking at a Responsible, Plural and Solidarity-Based Economy from Different Cultural Facets: Asia - Latin America - North America - Europe", 2009, PACS/ALOE/FPH, livreto contendo quatro estudos continentais sobre visõe de uma economia responsável, plural e solidária, concebido para estimular o diálogo intercultural.

Arruda, Marcos, 2009, "Educação para uma Economia do Amor: Educação da Práxis e Economia Solidária", livro, Ideias\&Letras, Aparecida do Norte, São Paulo.

\section{ANEXO 1}

O Anexo 1 apresenta os princípios fundamentais que orientam a prática da Economia

\section{Solidária:}

\section{PRINCÍPIOS DA ECONOMIA SOLIDÁRIA}

1. PROPRIEDADE/POSSE: direito de propriedade vinculado ao trabalho, não ao capital

2. CONSUMO CONSCIENTE: necessidades como referências - economia do suficiente - sobriedade feliz

3. COMPARTILHA o excedente e os ganhos da produtividade

4. TRABALHO EMANCIPADO: reduz ao mínimo o trabalho necessário - liberta da mera sobrevivência física

5. GANHA-GANHA: transparência de custos e preços-atitude de mutualidade

6. DINHEIRO sem usura
7. ATORES: SOCIEDADE consciente - unidades familiares, comunidades, associações e cooperativas e ESTADO orquestrador da sociodiversidade

8. LOGÍ́STICASOLIDÁRIA

9. REDES E FLUXOS produtivos e distributivos solidários

10. PLANEJAMENTO do DESENVOLVIMENTO: das comunidades até a nação, e de volta - trânsito para a globalização solidária 


\section{ANEXO 2}

O Anexo 2 apresenta uma visão abrangente da Economia Solidária como Sistema, feito de pelo menos cinco dimensões:

(1) o centro: o indíviduo social, ou o ser humano como indivíduo e ser eco-social ao mesmo tempo;

(2) suas relações: consigo mesmo, com a Natureza, com a Sociedade (sincrônica) e a Humanidade (diacrônica), e com cada outra pessoas;

(3) os quatro campos básicos da atividade socioeconômica, com seus atributos qualitativos: consumo consciente, produção autogestionária, comércio justo e finanças solidárias;

(4) as atividades complementares básicas que asseguram a abordagem integral da totalidade do ser humano: educação cooperativa; arte e comunicação em diálogo; pesquisa e desenvolvimento de tecnologias apropriadas aos diferentes ecossistemas; Estado e políticas públicas; legislação; ética, cultura e transformação pessoal e interpessoal.

(5) as emoções noológicas que são especificamente humanas e precisam ser educads e desenvolvidas por cada pessoa. Redes e fluxos de produção e distribuição solidários, constituem o nível meso. O trabalho emancipado, o desenvolvimento humano e social autogestionário, o Estado como orquestrador da diversidade social, e a integração regional solidária; todos estes abrangidos pelo ambiente natural.

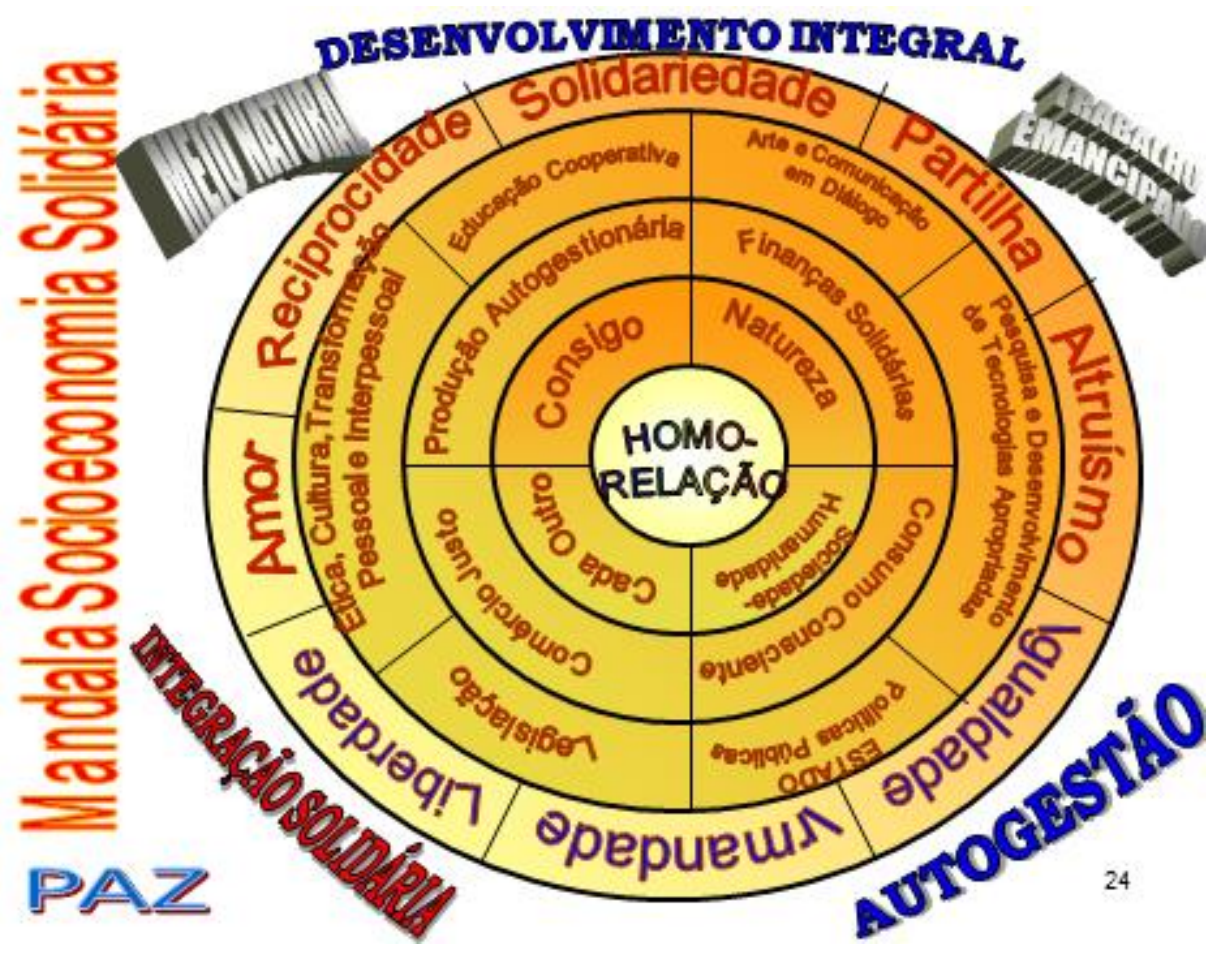




\section{ANEXO 3}

O Anexo 3 apresenta os passos para a transição da economia solidária para uma 'economia do amor'. O diagrama mostra dois triângulos invertidos (o masculino, com o vértice para cima, e o feminino, com o vértice para baixo), e o núcleo:

1) três formas e níveis de organização - cooperativas-associações, fluxos de produção e distribuição, e redes solidárias;

2) três modos/qualidades de gestão (ou de uso do poder) - autogestão, autonomia e solidariedade; e

3) três valores/atitudes fundamentais - autoestima, humildade e gratuidade.

Uma Economia do Amor se funda na gratuidade, no dom; não involve obrigação recíproca, mas sim um incondicional dar e receber. Isto é chamado de amor incondicional. Conceitualmente, pode ser derivado de uma situação de abundância de bens materiais para toda a sociedade, de tal forma que o comércio e o dinheiro se tornam supérfluos. Na prática, isto já é real em cada trabalho voluntário - especialmente das mulheres - que é oferecido em todo o mundo e que em 2010 alcançou, segundo a ONU, um valor equivalente a US\$ 16 trilhões.

Publiquei em 2009 o terceiro volume da minha trilogia, com o título de "Educação para uma Economia do Amor: Educação da Práxis e Economia Solidária". Mais tarde, descobri uma economista estadunidense, Hazel Henderson, que usa o mesmo conceito que eu, e com o mesmo sentido. Alguns dos seus livros são: "Paradigms in Progress", "Ethical Markets: Growing the Green Economy", "Building a Win-Win World - Life Beyond Global Economic Warfare".

\section{ECONOMIA SOLIDARIA E METANOIA}

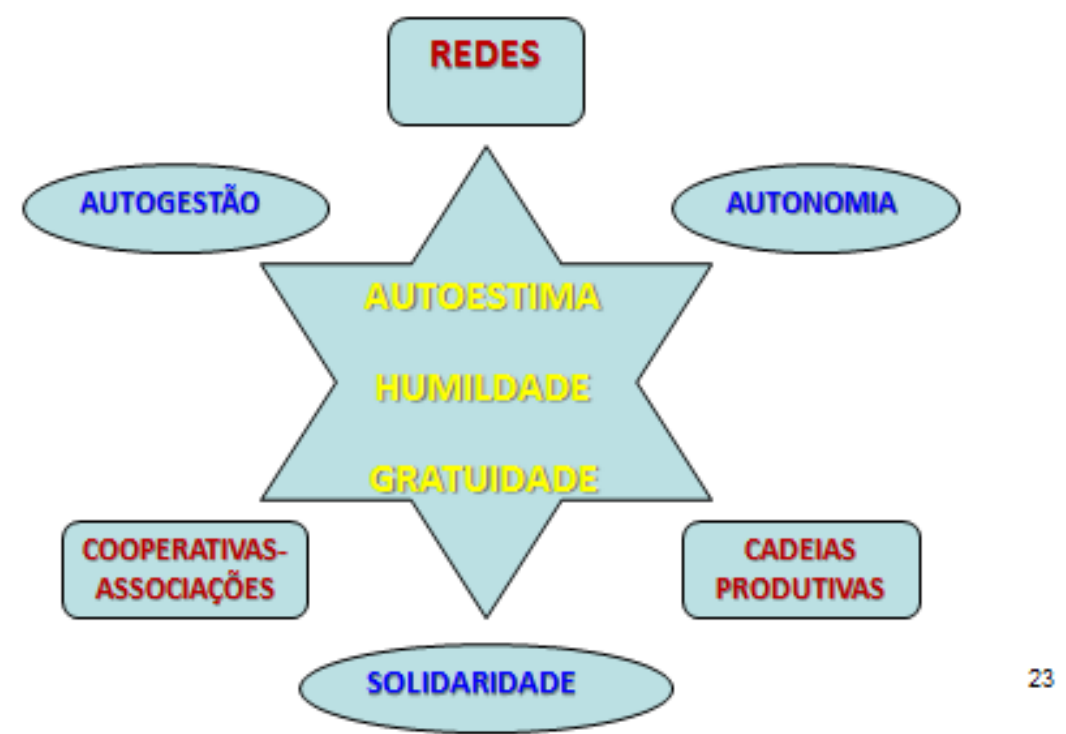




\section{Questões para reflexão:}

1. O desafio da sustentabilidade, na era das ameaças de catástrofes socioambientais, pode ser respondido eficazmente pela humanidade dentro do Sistema do Capital?

2. Se não, o que é preciso mudar para que a espécie humana se torne uma espécie sustentável no planeta?

3. O que está ao seu alcance para que esta mudança ocorra em tempo, e não tarde demais? 